University of Nebraska - Lincoln

DigitalCommons@University of Nebraska - Lincoln

Faculty Publications in Food Science and Technology

Food Science and Technology Department

2003

A Response Surface Analysis of Commercial Corn Starch Annealing

Serap Ozcan

University of Nebraska-Lincoln

David S. Jackson

University of Nebraska-Lincoln, djackson1@unl.edu

Follow this and additional works at: https://digitalcommons.unl.edu/foodsciefacpub

Part of the Food Science Commons

Ozcan, Serap and Jackson, David S., "A Response Surface Analysis of Commercial Corn Starch Annealing" (2003). Faculty Publications in Food Science and Technology. 96.

https://digitalcommons.unl.edu/foodsciefacpub/96

This Article is brought to you for free and open access by the Food Science and Technology Department at DigitalCommons@University of Nebraska - Lincoln. It has been accepted for inclusion in Faculty Publications in Food Science and Technology by an authorized administrator of DigitalCommons@University of Nebraska - Lincoln. 


\title{
A Response Surface Analysis of Commercial Corn Starch Annealing ${ }^{1}$
}

\author{
Serap Ozcan ${ }^{2}$ and David S. Jackson ${ }^{2.3}$
}

Cereal Chem. 80(2):241-243

Native starch is composed of granules that are organized, durable, and morphologically identifiable microscopic structures of amylose and amylopectin molecules (Virtanen and Autio 1993; Snyder 1984). Sahai and Jackson (1994) reported that native starch granules from a single starch source were not homogeneous in character and had different functional properties. Because of their heterogeneity, it should not be expected that starch granules behave uniformly when heated in water (Sahai and Jackson 1996). The extent of heat treatment, starch hydration, and the inherent physical and chemical properties of native starch determine the structure and functionality of starch in a food system. During heating of native starch in water, some changes occur such as loss of birefringence, loss of crystallinity, granule swelling, leaking of amylose and amylopectin molecules from disrupted granules, and gelatinization (Eliasson and Gundmusson 1996). Starch functionality in food is governed by the inherent chemical and physical properties of its structures. One of the starch forms that exists in certain food systems is annealed starch. For example, corn steeped for tortilla processing is considered to have annealed starch (Gomez et al 1992; Sahai et al 1999). Krueger et al (1987a) postulated that annealing occurs during commercial wet-milling of corn starch, sometime after steeping but before starch drying. Annealing is a physical treatment that modifies the chemical and physical properties of starch without destroying granular structure.

Stute (1992) defined annealing as "alterations within the crystallites of the granules". The annealing process requires incubation of granular starch in excess water, for a period of time at a temperature below the gelatinization temperature (Jacobs et al 1995; Slade and Levine 1988; Stute 1992). Gough and Pybus (1971) were among the first to describe the effect of annealing on wheat starch in water at $50^{\circ} \mathrm{C}$ using hot-stage microscopy. Their findings of increased peak gelatinization temperature and decreased gelatinization range were confirmed later by differential scanning calorimetry (DSC) experiments (Yost and Hoseney 1986; Krueger et al 1987a,b; Knutson 1990; Tester and Morrison 1990; Larsson and Eliasson 1991; Lopez and Lopez 1991; Stute 1992). An increase (Krueger et al 1987a,b; Knutson 1990; Hoover and Vasanthan 1994; Jacobs et al 1995) or no change (Yost and Hoseney 1986; Larsson and Eliasson 1991; Stute 1992; Jacobs et al 1995) in the gelatinization enthalpies were observed.

The degree of crystallinity in starch can be determined using X-ray diffraction techniques. Gough and Pybus (1971) observed no changes in X-ray patterns as a result of annealing. Jacobs et al (1998) also found no changes in crystal type and degree of crystallinity after one- and two-step annealing of wheat, potato, and pea starches. Annealing increases granular stability (Hoover and Vasanthan 1994), reorganizes granular structure (Krueger et al 1987a,b), and results in more organized structures with lower free energies (Blanshard

${ }^{1}$ Contribution of the University of Nebraska Agriculture Research Division. Lincoln, NE 68583. Joumal Series No. 13677.

${ }^{2}$ Graduate research assistant and professor, respectively, Department of Food Science and Technology, University of Nebraska, Lincoln, NE 68583-0919.

${ }^{3}$ Corresponding author. E-mail: djackson@unlnotes.unl.edu. Fax: 402-472-1693.

Publication no. C-2003-0214-04R

(C) 2003 American Association of Cereal Chemists, Inc.
1987). Some researchers, however, have discussed annealing in terms of starch crystallite perfection and starch crystallinity (Yost and Hoseney 1986; Tester and Morrison 1990; Larsson and Eliasson 1991), granule rigidity (Jacobs et al 1995), polymer chain realignment within granules and partial crystallite melting (Marchant and Blanshard 1980), binding force changes between crystallites and the amorphous matrix (Stute 1992), mobility differences in amorphous or crystalline regions (Nazakava et al 1984), and improved interactions between amylose and amylopectin (Knutson 1990).

Knutson (1990) found that a higher annealing temperature could be reached by a multistep procedure that involves first annealing at one temperature, then reannealing at a slightly higher temperature. Because the first annealing increases the onset temperature at which gelatinization starts, the sample could be held at a higher annealing temperature that is just below the new onset temperature without causing gelatinization. This process could be repeated until further annealing resulted in no increase in the onset temperature. It was also suggested that at the point where a starch reached its highest onset temperature, it presumably also had reached its highest possible degree of crystallinity; any further increase in temperature to attempt further annealing would result in gelatinization (Knutson 1990). This work was designed to determine the most suitable time and temperature conditions for the preparation of an annealed starch system. Such model systems are required to allow a more systematic study of these starch structures and their functionality. Studies of highly annealed starch granules can lead to an improved understanding of the complex physical structures of starch and the functional role of those structures in food. Information on the preparation of highly annealed starches is scarce.

\section{MATERIALS AND METHODS}

\section{Materials}

Regular corn starch, obtained from Cerestar USA (Hammond, IN) was used as a raw material in the preparation of annealed starch polymer systems. Because of the industrial process used to isolate this starch, it has likely already undergone some annealing.

\section{Experimental Design}

A response surface central composite design with two numeric factors (heating rate and annealing end temperature) was used. Annealing end temperature was defined as the highest temperature that was reached during the annealing process. The process variables were varied as described in Table I. A total of 13 experiments (Table II) with five center points, one replicate of four factorial points, and one replicate of four axial points were generated using statistical software (Design Expert, v. 6.0.5, StatEase, Minneapolis, MN).

\section{Preparation of Annealed Systems Using RVA}

The annealing process was performed in a Rapid Visco Analyser (RVA) (Series 4, Newport Scientific Warriewood, Australia) according to the Design Expert specified treatment combinations (Table II). Starch slurries were prepared by combining $3.0 \mathrm{~g}$ of starch and $30 \mathrm{~mL}$ of deionized distilled water in an aluminum cup containing a plastic paddle with a spin rate of $75 \mathrm{rpm}$. The anneal- 
ing start temperature was $45^{\circ} \mathrm{C}$ for all samples. After treatment, samples were freeze-dried.

\section{Differential Scanning Calorimetry}

Differential scanning calorimetry (DSC) endotherms of starch samples were obtained (Pyris 1, Perkin Elmer, Norwalk, CT). Indium was used to calibrate the DSC and a sealed empty pan was used as the reference pan. Freeze-dried treated starch samples (9$10 \mathrm{mg}, \mathrm{db}$ ) were weighed into large aluminum pans (LVC 03190029 , Perkin-Elmer). Distilled water was added in excess $(\approx 80 \%$, $\mathrm{w} / \mathrm{v})$ and pans were hermetically sealed, equilibrated overnight at $20^{\circ} \mathrm{C}$, and heated from 25 to $125^{\circ} \mathrm{C}$ at a $5^{\circ} \mathrm{C} / \mathrm{min}$ heating rate. DSC parameters such as peak onset temperatures and enthalpies were calculated from the endotherms. For each treatment, DSC data was collected three times and averaged.

\section{X-ray Diffraction}

$X$-ray diffraction patterns of starch samples were obtained on an $\mathrm{X}$-ray diffractometer (Rigaku Denki, Japan) with Rigaku DMAX-B software (v. 3.0). The freeze-dried samples were smeared with 2-3 drops of ethanol on a zero cavity flat-mount (glass) and allowed to dry. Samples were equilibrated at room temperature and humidity. Prepared slides were put individually into sample holder in the diffractometer and scanned from $2 \theta=12-27^{\circ}$ with $1 \% 1-\mathrm{min}$ increments. The X-ray diffractometer was operated at $1.8 \mathrm{~kW}$ load with $40 \mathrm{kV}$ tube voltage and $30 \mathrm{~mA}$ tube current. The diffraction patterns were analyzed using MacDiff X-ray diffraction peak analysis software (v. 4.2.5). The relative degree of crystallinity was measured quantitatively by connecting the lowest points between diffraction peaks with a smooth curve. The area under the peaks was calculated as the crystalline component and area under the smooth curve was calculated as amorphous component as specified by Roe (2000).

\section{Optimization}

Optimization is performed by attempting to combine various factors (levels) that simultaneously satisfy the requirements placed on each of the responses and factors. For simultaneous optimization, each response was assigned a goal. For example, the value of a variable could be maximized, minimized, have a specific numerical target, or fall within a specific numerical range. Response surface methodology (RSM) data was used to determine the optimal conditions for producing an annealed sample with high (maximized) gelatinization enthalpies and onset temperatures, but without a reduction in \%crystallinity (falls within a numerical range). RSM model equations were generated, and insignificant terms were removed using backwards model reduction. Model $R^{2}$ and $P$ values and lack of fit (LOF) $P$ values were reported (LOF should be insignificant). A run at the calculated optimized heating rate and annealing end temperature was also performed to confirm the optimization. Desirability is an objective function that ranges from 0 outside of the limits to 1 at the goal. Numerical optimization finds a point

TABLE I

Annealing Process Variables, Heating Rate $\left({ }^{\circ} \mathrm{C} / \mathrm{hr}\right)$ and Annealing End Temperature $\left({ }^{\circ} \mathrm{C}\right)$

\begin{tabular}{lcc}
\hline Factor & $\begin{array}{c}\text { Low Level } \\
\text { (actual) }\end{array}$ & $\begin{array}{c}\text { High Level } \\
\text { (actual) }\end{array}$ \\
\hline Heating rate $\left({ }^{\circ} \mathrm{C} / \mathrm{hr}\right)$ & 0.5 & 1.5 \\
Annealing end temperature $\left({ }^{\circ} \mathrm{C}\right)$ & 50 & 65 \\
\hline
\end{tabular}

TABLE II

Response Surface Methodology (RSM) Treatment Combinations for Annealing

\begin{tabular}{ll}
\hline Design Points & Heating Rate $\left({ }^{\circ} \mathbf{C} / \mathbf{h r}\right) \times$ Annealing End Temp. $\left({ }^{\circ} \mathbf{C}\right)$ \\
\hline Center (5) & $1.00 \times 57.5$ \\
Axial (1) & $1.50 \times 65.0,150 \times 50.0,0.50 \times 50.0,0.5 \times 65.0$ \\
Factorial (1) & $1.71 \times 57.5,0.29 \times 57.5,1.00 \times 46.9,1.00 \times 68.1$ \\
\hline
\end{tabular}

that maximizes the desirability function. For several responses, all goals were combined into one desirability function as in Equation 1 (Myers and Montgomery 1995).

$$
D=\left(\mathrm{d}_{1} * \mathrm{~d}_{2} * \mathrm{~d}_{3} * \ldots * \mathrm{~d}_{\mathrm{n}}\right)^{1 / \mathrm{n}}=\left[\prod_{\mathrm{i}=1}^{\mathrm{n}} \mathrm{d}_{\mathrm{i}}\right]^{1 / \mathrm{n}}
$$

where $D=$ geometric mean of all transformed responses and $n=$ number of responses in the measure.

\section{RESULTS}

RSM graphs and equations are shown in Fig. 1. The commercial corn starch had an onset temperature of $67.6^{\circ} \mathrm{C}$, peak temperature of $72.2^{\circ} \mathrm{C}$, enthalpy of $13.0 \mathrm{~J} / \mathrm{g}$ and a $49.6 \%$ crystallinity. RSM data indicated that treated sample onset temperatures were not statistically influenced by heating rate, but highly influenced by end temperature (reduced quadratic model, $R^{2}=0.92, P<0.05$, LOF $P=0.62$ ). The \%crystallinity was not statistically influenced
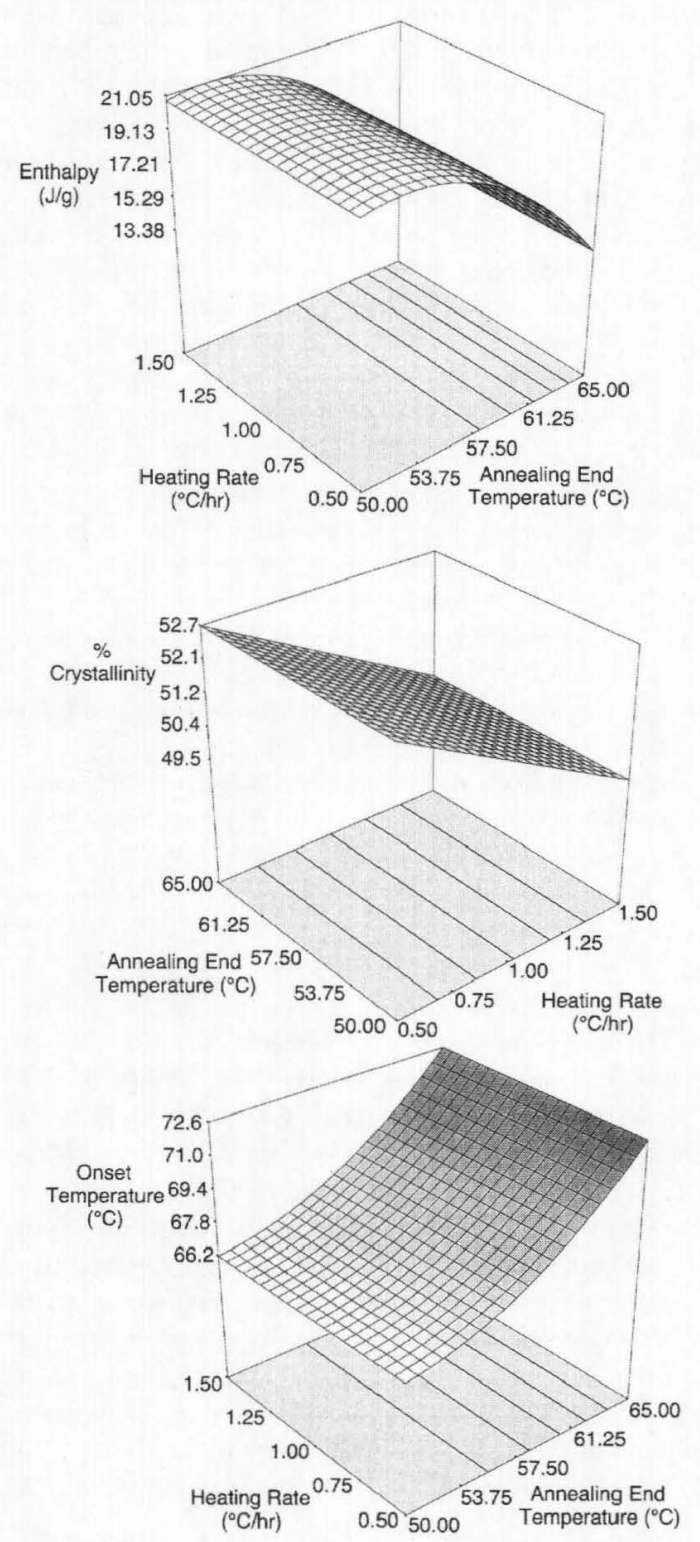

Fig. 1. Response surface methodology (RSM) graphs for enthalpy, onset temperature and \% crystallinity. RSM equations for each graph: Enthalpy $=-113.137+5.117 \times$ annealing end temp. $-0.048776 \times$ annealing end temp ${ }^{2}$; Onset temperature $=+118.603-2.180 \times$ annealing end temp $+0.023 \times$ annealing end temp $\mathrm{p}^{2} \%$ Crystallinity $=+54.702-$ $3.459 \times$ heating rate. Additional statistical information for each model is in text. 
by annealing end temperature, but influenced by heating rate within a small \%crystallinity range $(49.5-53.0 \%)$ (reduced linear model, $R^{2}=0.41, P<0.05$, LOF $P=0.27$ ).

Sample enthalpy was not statistically influenced by heating rate, but highly influenced by end temperature (reduced quadratic model, $R^{2}=0.87, P<0.05$, LOF $P=0.52$ ). Optimization was performed by maximizing enthalpy $(14.2 \mathrm{~J} / \mathrm{g})$, maximizing onset temperature $\left(69.0^{\circ} \mathrm{C}\right)$ and holding crystallinity unchanged (target) $(52.4 \%)$. A desirability of 0.923 , a peak temperature of $73.2^{\circ} \mathrm{C}$, and an enthalpy of $14.2 \mathrm{~J} / \mathrm{g}$ were calculated with an annealing end temperature of $59.3^{\circ} \mathrm{C}$ and heating rate of $0.67^{\circ} \mathrm{C} / \mathrm{hr}$. Similar results for enthalpy $(13.7 \mathrm{~J} / \mathrm{g})$, onset temperature $\left(68.7^{\circ} \mathrm{C}\right)$, and \%crystallinity $(53.6 \%)$ were obtained when a run was performed using the RSM calculated optimal annealing end temperature $\left(59.3^{\circ} \mathrm{C}\right)$ and heating rate $\left(0.67^{\circ} \mathrm{C} / \mathrm{hr}\right)$.

\section{DISCUSSION AND CONCLUSIONS}

Response surface statistical design can be used to optimize the preparation of annealed samples from commercial corn starch. Within the range of tested process conditions (annealing heating rate and annealing end temperature), DSC gelatinization enthalpy, and onset temperature were maximized and \%crystallinity could be maintained. When mathematically determined conditions were tested, actual and calculated results for DSC gelatinization enthalpy and onset temperature, and \%crystallinity were similar. This annealed starch will be used in model systems to further understand starch structures and their contribution to starch functionality and physicochemical properties. The application of continuous annealing using RVA allows for more controlled annealing conditions than multistep annealing that uses long annealing times at specific static temperatures. Using our experimental protocol, because heating rate does not impact either gelatinization enthalpy or onset temperature, and has a little impact on \%crystallinity (small impact within a very narrow \%crystallinity range), the use of continuous annealing instead of multistep annealing is preferable.

\section{LITERATURE CITED}

Blanshard, J. M. V. 1987. Starch granule structure and function: A physicochemical approach. Pages 16-54 in: Starch: Properties and Potential. T. Galliard, ed. John Wiley and Sons: Chichester, UK.

Eliasson, A. C., and Gundmusson, M. 1996. Starch: Physiochemical and functional aspects. Pages $431-503$ in: Carbohydrates in Food. A. C. Eliassson, ed. Marcel Dekker: New York.

Gomez, M. H., Lee, J. K., McDonough, C. M., Waniska, R. D., and Rooney, L. W. 1992. Corn starch changes during tortilla and tortilla chip processing. Cereal Chem. 69:275-279.

Gough, B. M., and Pybus, J. N. 1971. Effect on the gelatinization temperature of wheat starch granules of prolonged treatment with water at $50^{\circ} \mathrm{C}$. Starch. 23:210-212.
Hoover, R., and Vasanthan, T. 1994. The effect of annealing on the physicochemical properties of wheat, oat, potato and lentil starches. J. Food Biochem. 17:303-305.

Jacobs, H., Eerlingen, R. C.. Clauwaert, W., and Delcour, J. A. 1995. Influence of annealing on the pasting properties of starches from varying botanical sources. Cereal Chem. 72:480-487.

Jacobs, H., Mischenko, N., Koch, M. H. J., Eerlingen, R. C., Delcour, J. A., and Reynaers, H. 1998. Evaluation of the impact of annealing on gelatinization at intermediate water content of wheat and potato starches: A differential scanning calorimetry and small-angle X-ray scattering study. Carbohydr. Res. 306:1-10.

Knutson, C. A. 1990. Annealing of maize starches at elevated temperatures. Cereal Chem. 67:376-384.

Krueger, B. R., Knutson, C. A., Inglett, G. E. and Walker, C. E. 1987a. A differential scanning calorimetry study on the effect of annealing on gelatinization behavior of corn starch. J. Food Sci. 52:715-718.

Krueger, B. R., Walker, C. E., Knutson, C. A., and Inglett, G. E. $1987 \mathrm{~b}$. Differential scanning calorimetry of raw and annealed starch isolated from normal and mutant maize genotypes. Cereal Chem. 64:187-190.

Larsson, I., and Eliasson, A. C. 1991. Annealing of starch at an intermediate water content. Starch 43:227-231.

Lopez, O. P., and Lopez, D. H. 1991. Application of differential scanning calorimetry to amaranth starch gelatinization: Influence of water solutes and annealing. Starch 43:57-61.

Marchant, J. L., and Blanshard, J. M. V. 1980. Changes in the birefringent characteristics of cereal starch granules at different temperatures and water activities. Starch 32:223-226.

Myers, R. H., and Montgomery, D. C. 1995. Response Surface Methodology: Process and Product Optimization Using Designed Experiments. John Wiley and Sons: New York.

Nazakawa, F., Noguchi, S., Takahashi, J., and Takada, M. 1984. Thermal equilibrium state of starch-water mixture studies by differential scanning calorimetry. Agric. Biol. Chem. 48:2647-2653.

Sahai, D., and Jackson, D. S. 1994. Structure and chemical properties of partially heated corn starch granules. Starch 46:457-463.

Sahai, D., and Jackson, D. S. 1996. Structural and chemical properties of native corn starch granules. Starch 48:249-255.

Sahai, D., Mua, J. P., Surjewan, I., Buendia, M. O., Rowe, M., and Jackson, D. S. 1999. Assessing degree of cook during corn nixtamalization: Impact of processing variables. Cereal Chem. 76:850-854.

Slade, L., and Levine, H. 1988. Non-equilibrium melting of native granular starch. I. Temperature location of the glass transition associated with gelatinization of A-type cereal starches. Carbohydr. Polym. 8:183-203.

Snyder, E. M. 1984. Industrial microscopy of starches. Pages 661-675 in: Starch: Chemistry and Technology, 2nd Ed. R. L. Whistler, J. N. BeMiller, and E. F. Paschall, eds. Academic Press: Orlando, FL.

Stute, R. 1992. Hydrothermal modification of starches: The difference between annealing and heat-moisture treatment. Starch 44:205-214.

Tester, R. F., and Morrison, W. R. 1990. Swelling and gelatinization of cereal starches. II. Waxy rice starches. Cereal Chem. 67:558-563.

Virtanen, T., and Autio, K. 1993. The microscopic structure of rye kernel and dough. Carbohydr. Polym. 21:97.

Yost, D. A., and Hoseney, R. C. 1986. Annealing and glass transition of starch. Starch 38:289-292.

[Received April 17, 2002. Accepted November 3, 2002.] 